\title{
Development of pseudoboehmites for nanosystems to release acyclovir
}

\author{
A. H. MUNHOZ JR., ${ }^{1, a}$, R. W. NOVICKIS ${ }^{1, b}$, S. B. FALDINI ${ }^{1, c}$, \\ R. R. RIBEIRO ${ }^{1, d}$, C. Y. MAEDA ${ }^{1, \mathrm{e}}$, L. F. DE MIRANDA ${ }^{1, f}$ \\ ${ }^{1}$ Universidade Presbiteriana Mackenzie - Rua da Consolação, 930 - Cep 01302-907 - São Paulo - \\ SP - Brazil
}

aantonio.munhoz@mackenzie.br, bahmunhoz@yahoo.com, 'sfaldini@yahoo.com.br,

dccbs.farmacia@mackenzie.br , eengmateriais@mackenzie.br, flfmiranda@sti.com.br

Key-words: drug delivery system, drugs, pseudoboehmite, acyclovir.

The production of confined or adsorbed drugs in inorganic matrix has been increasing in areas like material science and pharmaceutical due to the possibility of the production of nanoadsorbed or encapsulated molecules with new properties like chemical stability, enhancing solubility and controlled release, what implies in new applications of materials. In the present work, a nanocomposite of a fine ceramic material, pseudoboehmite, and acyclovir, was prepared. Pseudoboehmite is based on a monohydroxide aluminum oxide produced from a synthetic route using ammonium hydroxide and aluminum nitrate or chloride as precursors in the sol-gel process. These systems had been characterized by the following techniques: MEV, TG/DSC, FTIR and UVvis. The exposition of the drug to the pseudoboehmite at the dissolution equipment was at $37^{\circ} \mathrm{C}$ and $100 \mathrm{rpm}$ for 30 minutes. With the purpose to observe the interaction of the drug with the adsorbent, it was obtained the concentration of the drug in the solution, before and after the adsorption, using the UV-vis spectroscopy technique. The acyclovir has increased its solubility in an $\mathrm{HCl} 0,1 \mathrm{M}$ solution, when the weight ratio of Pseudoboehmite: Acyclovir 1:1 was used.

\section{Introduction}

In recent years, the interest in nanosystems in pharmacy has surged due to the advantages that these systems may provide over the existing systems. The design of drug delivery systems is challenging in terms of targeting the drug to specific place. Some drugs that show success in cell culture fail in producing the same effect in the human body because of the limitation to target the designated area. Due to this fact high concentrations are given to patients resulting in more intense side effects. Besides that many drugs require special formulations to overcome problems associated with the drugs such as drug instability, poor solubility, potentially side effects etc. Poor bioavailability far too often results in not only higher patient costs and inefficient treatment, but also, more importantly, increased risks of toxicity or even death [1]. Acyclovir is a drug with poor solubility and only $20 \%$ of the drug is effectively absorbed from the patient during his treatment.

Nanoparticles are tiny materials with specific physicochemical properties different to bulk materials of the same composition. The nanoparticles can act on living cells at the nanolevel resulting in biologically desirable effects. The ceramic nanoparticles are biocompatible inorganic systems with porous characteristics that can be used in cancer therapy. Among the ceramic nanoparticles there are silica, Titania, alumina etc [2].

The sol-gel synthesis is a promising process for obtaining pseudoboehmite and high surface area alumina with controlled pore diameter [3]. The structure of pseudoboehmite is similar to the structure of boehmite. They have similar peak positions on their diffraction patterns. The structure of boehmite consists of double layers of oxygen octahedral partially filled with Al cations. 
Boehmite has the same structure as lepidocrocite $(\gamma-\mathrm{FeO}-(\mathrm{OH}))$. It is orthorhombic with space group Amam $(\mathrm{a}=3.6936 \AA, \mathrm{b}=12.214 \AA, \mathrm{c}=2.8679 \AA)$. The difference between boehmite and pseudoboehmite is that there are additional water molecules in the pseudoboehmite at the unit cell that results in a bigger unit cell than the one of boehmite. Water molecules usually are considered to be introduced in the interlayer space [4]. According to Moroz et al [5], the changes in the local structure of layers of pseudoboehmite structure seem to be due to the formation of new bonds between the molecules of water and ions of the layers. The calcination of pseudoboehmite produces the same aluminas of boehmite calcination according with Eq. 1.

pseudoboehmite $\rightarrow \gamma \rightarrow \delta \rightarrow \theta \rightarrow \alpha$-alumina

\section{Experimental}

The pseudoboehmite was produced with $\left(\mathrm{Al}\left(\mathrm{NO}_{3}\right)_{3} \cdot 9 \mathrm{H}_{2} \mathrm{O}\right)(980 \mathrm{~g}$ aluminum nitrate/1 L water), $\mathrm{NH}_{4} \mathrm{OH}$ water solution $(28 \mathrm{wt} \%)$ and polyvinyl alcohol $\left(\left[\mathrm{C}_{2} \mathrm{H}_{4} \mathrm{O}\right] \mathrm{n}\right)$ solution $(8 \mathrm{wt} \%$ in water $)$ to increase the viscosity. The sol-gel procedure used to produce the pseudoboehmite is described in a previous paper [3].

Characterization methods for the pseudoboehmite

$X$-rays powder diffraction: For the samples dried at $70^{\circ} \mathrm{C} / 24$ hour's diffraction data were recorded with a Rigaku MultiFlex difractometer with a fixed monocromator. The experimental conditions were: $40 \mathrm{kV}, 20 \mathrm{~mA}, 20^{\circ}<2 \theta<100^{\circ}, \Delta 2 \theta=0.02^{\circ}, \lambda \mathrm{CuK} \alpha$ at room temperature. The collected data were compared with the ICDD data.

Scanning electron microscopy: Scanning electron microscopy (SEM) images were taken with Phillips XL30 equipment using secondary electron detector. The powder was placed upon SEM stubs covered with double-face tape and covered with gold in an Edwards Sputter Coater model S150B. The images were registered under magnifications of $200 \mathrm{X}$ and $6000 \mathrm{X}$.

Thermal analyses: The thermo gravimetric analysis (TG) and differential scanning calorimetry (DSC) were performed in a Netzsch-STA409C equipment; heating from room temperature to

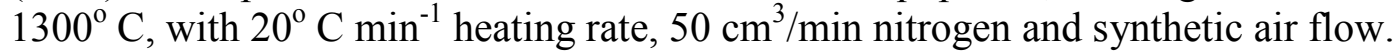

"in vitro" tests using $U V$-vis spectroscopy

The mixture of pseudoboehmite and acyclovir solution was made with the purpose to observe the influence of pseudoboehmite in acyclovir solubility.

Acyclovir Calibration curve

The calibration curve using UV-vis of acyclovir concentration was realized according to Farmacopeia Portuguesa VII using Beer-Lambert law. The wave length used was $\lambda=270 \mathrm{~nm}$. The acyclovir solution was prepared using $5 \mathrm{~g}$ of acyclovir in 1 liter of hydrochloric acid $0,1 \mathrm{M}$. This solution is not clear probably to the poor solubility of acyclovir.

Acyclovir pseudoboehmite mixture

The adsorption test was realized using $900 \mathrm{~mL}$ of acyclovir solution $(5 \mathrm{~g}$ acyclovir/L in $0,1 \mathrm{M}$ hydrochloric acid) and $5 \mathrm{~g}$ of pseudoboehmite. The mixture of acyclovir solution and pseudoboehmite was realized in an apparatus (Figure 1) suggested by United States Pharmacopoeia" USP at $37^{\circ} \mathrm{C}$ with $100 \mathrm{rpm}$ during 30 minutes. After that the pseudoboehmite was separated of the acyclovir solution by filtration. The pseudoboehmite with acyclovir adsorbed was used for the infrared absorption spectroscopy analysis.

Acyclovir release by pseudoboehmite

The pseudoboehmite with adsorbed acyclovir was used for the test of prolonged release (120 minutes) using the same apparatus of Figure 1. The acyclovir concentration was determined by the acyclovir calibration curve using UV-vis spectroscopy. 


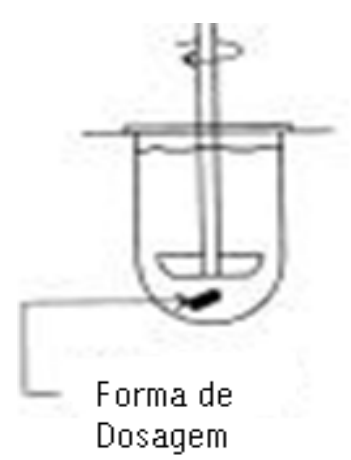

Figure 1. USP apparatus.

Chromatography of the released acyclovir

With the purpose to confirm the acyclovir presence released from pseudoboehmite in the solution, the solution with released acyclovir was analyzed by high performance liquid chromatography (HPLC) using a Dionex equipment. The reverse phase column (RP-C18) and a Dionex UV-vis detector with the wavelength of $254 \mathrm{~nm}$ were used for this purpose.

Infrared absorption spectroscopy

The infrared spectrum of the pseudoboehmite/acyclovir adsorbed was obtained using a Perkim Elmer equipment model Spectrum BX.

\section{Results and discussion}

SEM

The materials surface has a high porosity level, as can be seen through the SEM analysis, Figure 2.

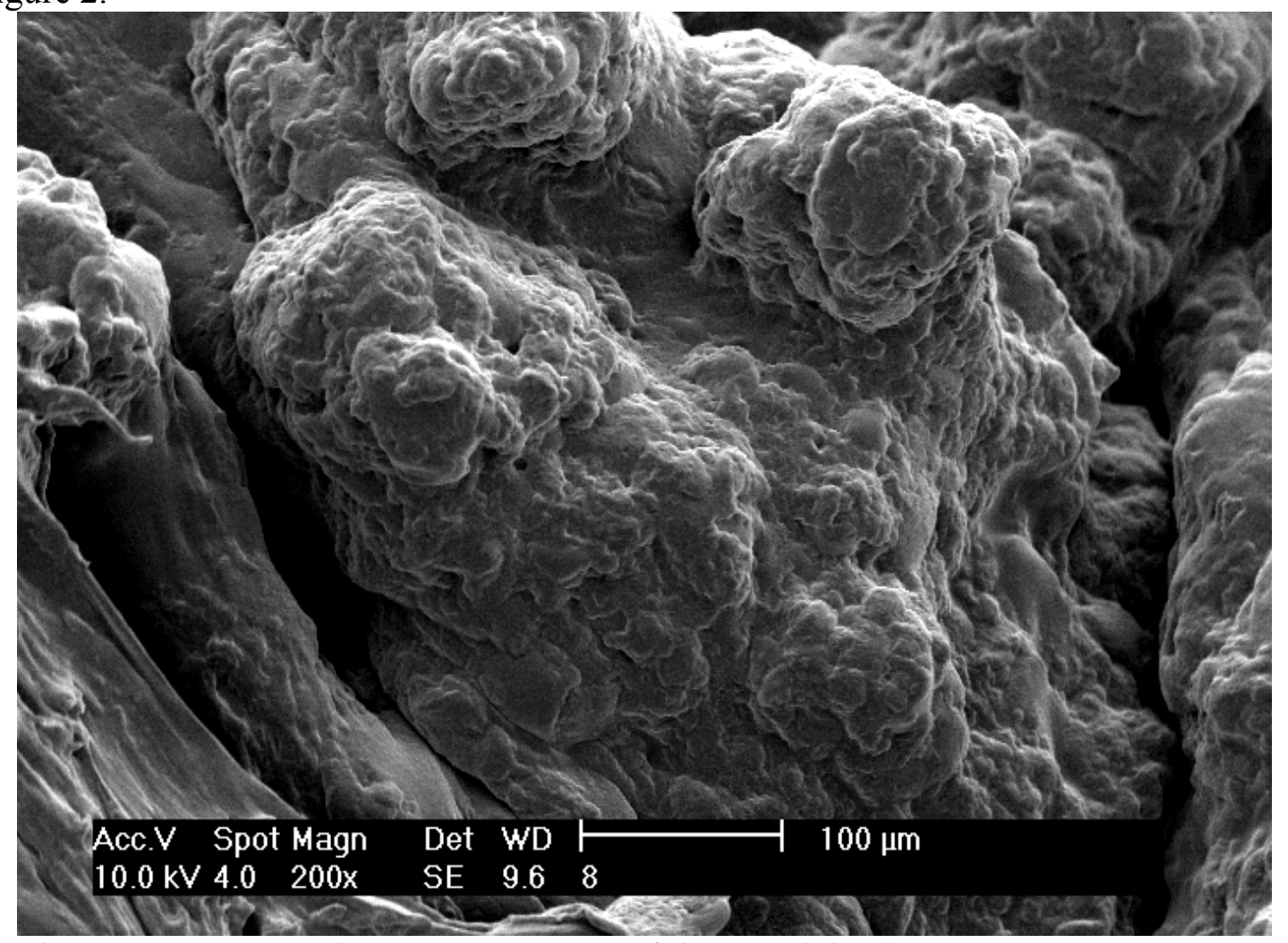

Figure 2. Scanning electron microscopy of the pseudoboehmite

\section{$X$-ray diffraction}

The X-ray diffraction data, Figure 3, shows the typical pseudoboehmite diffraction patterns with not intense peaks observed at $2 \theta=13^{\circ}(020)$ and $28^{\circ}(021)$. 


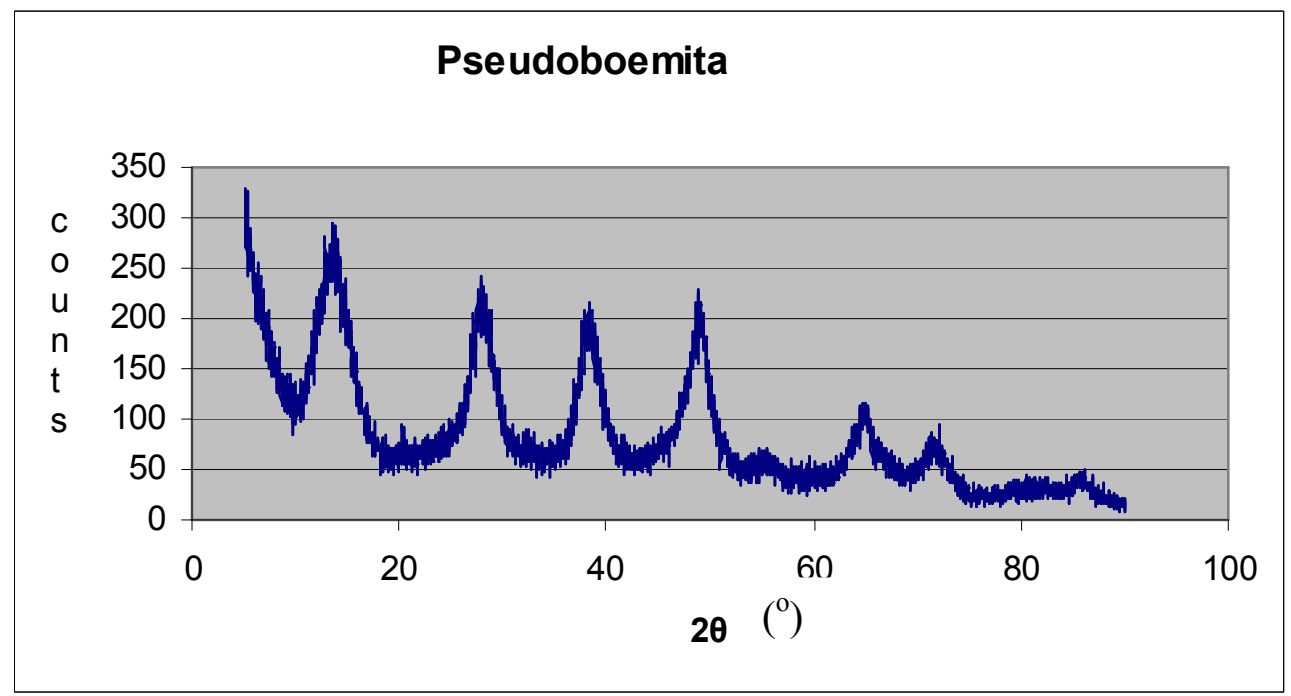

Figure 3. X-ray diffraction pattern of the pseudoboehmite

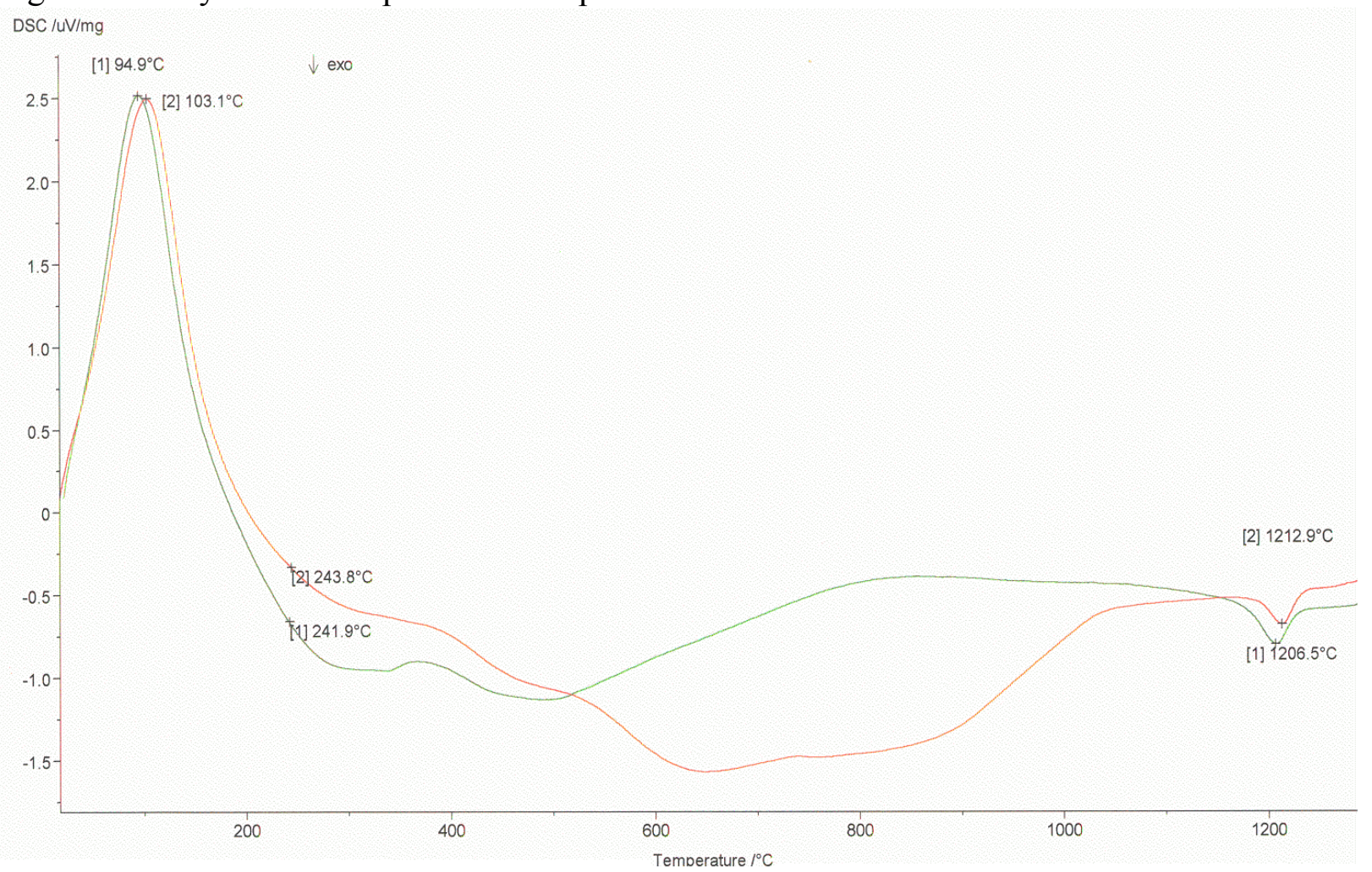

Figure 4. DSC of the pseudoboehmite sample. Nitrogen (red line - 2) and synthetic air (green line - 1).

The typical curve of theDSC for pseudoboehmite shows an endothermic peak near the temperature of $100^{\circ} \mathrm{C}$, due to water vaporization (Figure 4). The transformation of pseudoboehmite to $\gamma$-alumina and the decomposition of PVAl in the same range temperature of the DSC analysis show a complex peak in the range of $200-400^{\circ} \mathrm{C}$. In the DSC analysis at around $1200^{\circ} \mathrm{C}$ a peak is observed and attributed to the transformation of the last meta-stable phase of alumina to $\alpha$-alumina.

Infrared absorption spectroscopy analysis

In the Infrared absorption spectroscopy analysis, the infrared spectrum of the pseudoboehmite/acyclovir showed the predominance of pseudoboehmite spectrum. 


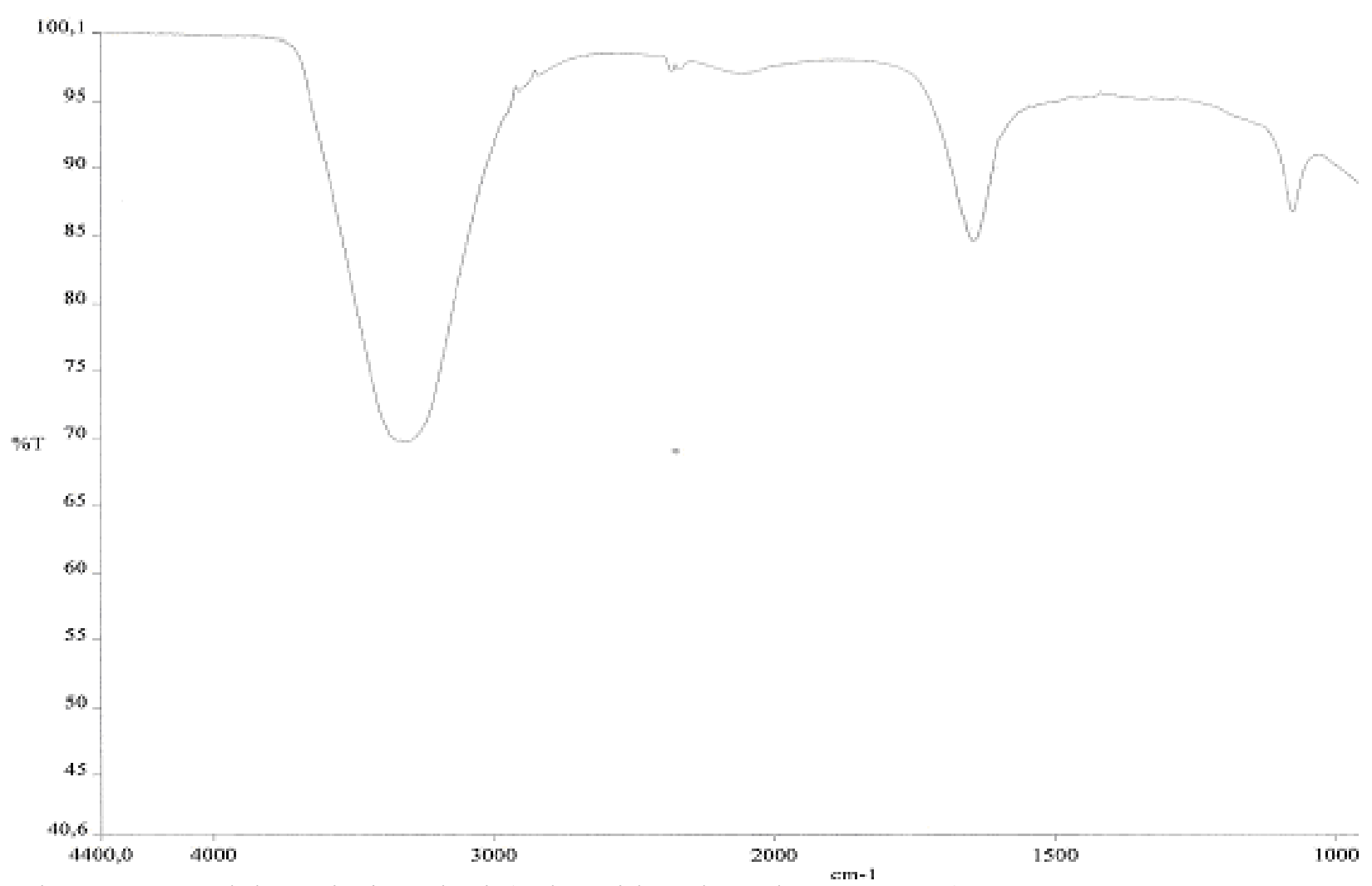

Figure 5: Pseudoboemita/acyclovir( adsorvido sob $\mathrm{HCl} 0,1 \mathrm{M}, \mathrm{pH}=1$ ).

Acyclovir release by pseudoboehmite

The acyclovir release is showed in Figure 6. It is observed a very good estability of the concentration in the range of 510 and $480 \mu \mathrm{g} / \mathrm{mL}$.

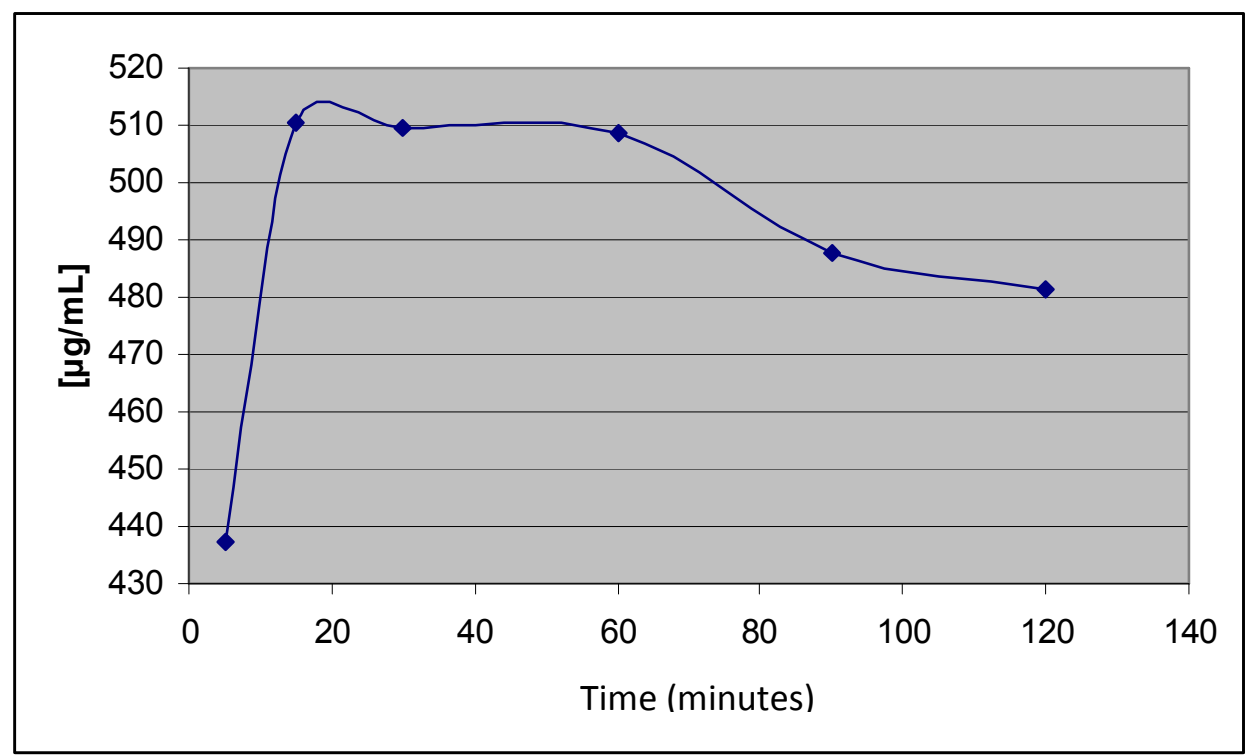

Figure 6. Acyclovir released by pseudoboehmite during 2 hours. Acyclovir concentration determined by Uv-vis spectroscopy.

Chromatography of the released acyclovir

Figure 7 shows the chromatogram obtained in the HPLC analysis for the acyclovir solution released from pseudoboehmite. The retention time for acyclovir (standard and released from pseudoboehmite) are equal. This is a clue of the chemical stability of acyclovir after the sorption in pseudoboehmite. This retention time is the same in the literature [6]. 


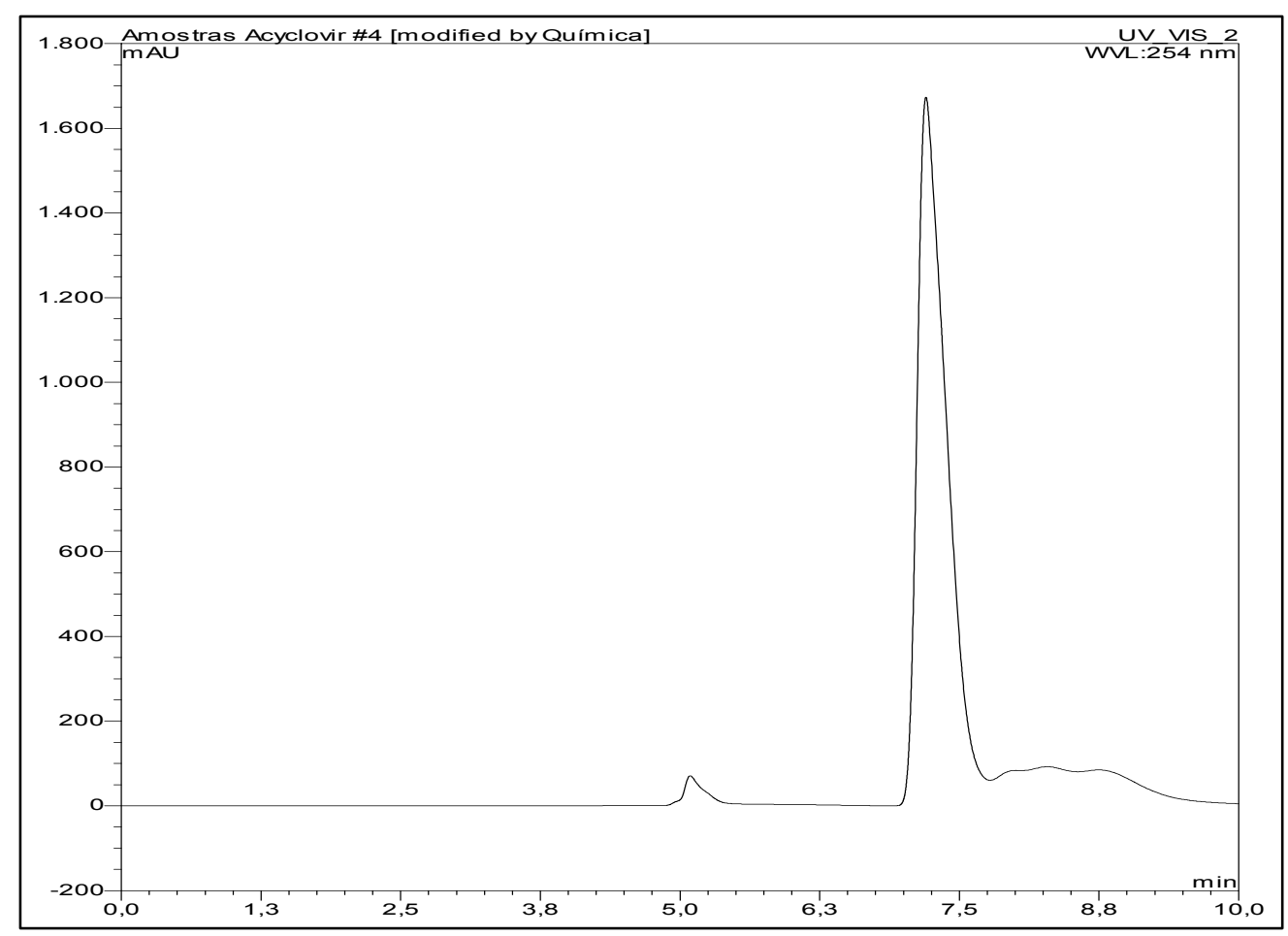

Figure 7. HPLC analysis of acyclovir solution released from pseudoboehmite.

\section{Conclusions}

The x-ray diffraction data and the DSC analysis show the typical results for the pseudoboehmite as related in the literature. The scanning electron micrograph shows that the product of the sol-gel synthesis is a very porous material. The tests of adsorption and release acyclovir from pseudoboehmite show that during the 120 minutes period the concentration of acyclovir was kept between 510 and $480 \mu \mathrm{g} / \mathrm{mL}$. The HPLC analysis shows that the released acyclovir has the same retention time of the standard acyclovir solution. This indicates the chemical stability of acyclovir during the adsorption process.

\section{References}

[1] Manju RAWAT, Deependra SINGH, S. SARAF, and Swarnlata SARAF, Nanocarriers: Promising Vehicle for Bioactive Drugs, Biol. Pharm. Bull. 29(9) 1790-1798 (2006)

[2] C Medina, MJ Santos-Martinez, A Radomski, OI Corrigan and MW Radomski, Nanoparticles: pharmacological \& toxicological significance,British Journal of Pharmacology(2007)150,552-558

[3] MUNHOZ JR, A. H., MIRANDA, L. F., UEHARA, G. N. Study of pseudoboehmite by sol-gel synthesis. AST - Advances in Science and Technology. , v.45, p.260 - 265, 2006.

[4] THEO KLOPROGGE, J.; DUONG, L.V.; WOOD, B.J.; FROST, R.L. XPS study of the major minerals in bauxite Gibbsite, bayerite and (pseudo-)boehmite, Journal of colloid and interface Science, v. 296, p.572-576, 2006.

[5] MOROZ, E.M.; SHEFER, K.I.; ZYUZIN, DMITRY A.; IVANOVA, ALEKSANDRA S.; KULKO, EUGENIA V.; GOIDIN, VASILY V. and MOLCHANOV, VIKTOR V. Local structure of pseudoboehmites, React.Kinet.Catal.Lett, Vol. 87, No. 2, 367-375, (2006).

[6] STULZER, H.K., TAGLIARI, M.P., SILVA, M.A.S., LARANJEIRA, M.C.M. Desenvolvimento, Avaliação e Caracterização Físico-Química de Micropartículas Constituídas de Aciclovir/Quitosana Desenvolvidas pela Técnica de Spray-drying Latin American Journal of Pharmacy (formerly Acta Farmacéutica Bonaerense)Lat. Am. J. Pharm. 26 (6): 866-71 (2007).

Acknowledgement: This research has been supported by the Mack Pesquisa and the Universidade Presbiteriana Mackenzie. We thank both for the support. 